\title{
Physiological and behavioural response of two dairy cows' genotypes during summertime in the central region of Chile
}

\author{
Rodrigo A. Arias ${ }^{\mathrm{a}}$, Camila Herrera ${ }^{\mathrm{b}}$, Rafael Larraín ${ }^{\mathrm{b}}$, Fernando González ${ }^{\mathrm{b}}$, \\ Terry L. Mader ${ }^{\mathrm{c}}$, Alejandro Velásquez ${ }^{\mathrm{d}}$
}

\begin{abstract}
Heat stress has been recognised as a serious problem in dairy farms. The study goal was to assess the effects of climatic conditions on physiological and behavioural responses of dairy cows in Central Chile. Data of tympanic temperature (TT), panting score, respiration rate (RR), and shade utilization of cows from two genotypes, Holstein (H) and Holstein x Montbeliarde (HM), were collected twice per day (AM/PM) during three periods of the summer season in Central Chile. Moreover, three thermal comfort indices: Comprehensive climate index (CCI), temperature humidity-index (THI), and adjusted THI were estimated using meteorological data. The hour of each day was classified as "Normal" or "Stressful" based on CCI threshold of $25^{\circ} \mathrm{C}$. Statistical analysis included ANOVA, repeated measures analysis and Chi square test $(\alpha=0.05)$. There was an interaction of genotype $\mathrm{x} C \mathrm{CI}$ condition $\mathrm{x}$ period $(P=0.0026)$ with the highest TT of both genotypes under a stressful condition within each period. In addition, interactions of genotype $\mathrm{x}$ hour $(P<0.0001)$ and genotype $\mathrm{x} C \mathrm{CI}$ condition $(P<0.0002)$ were also observed. The HM cows showed greater TT than $\mathrm{H}$ cows in both CCI conditions. The RR was higher during the afternoon and a greater proportion of cows used shade at "Mild" and "Moderate" $\mathrm{CCI}$ categories $(P<0.001)$. Both genotypes showed some degree of heat stress, but cool nights and shade seem to be enough to allow to cows' cope with the challenging diurnal conditions observed in the summer season. A study of these effects on milk production is necessary to confirm or discard the previous.

Key words: tympanic temperature, thermal comfort, respiration rate, heat stress.
\end{abstract}

\section{INTRODUCTION}

Heat stress has been recognised as a serious problem around the world, but especially on dairy farms using breeds with a high potential of milk production (Arias et al 2008, Silanikove 2000). Usually, these animals fail to maintain an adequate thermal balance causing negative consequences for milk production and animal welfare (Collier et al 2006, Kadzere et al 2002). The poor performance and efficiency in milk yield have been associated mainly with a decrease in dry matter intake (West 2003), resulting in significant economic losses (St-Pierre et al 2003), estimated to be $\$ 897$ million only for the dairy industry at the USA. A summary of the major behavioural responses includes changes on feeding, defecating and urinating frequency, water intake, lying time, standing time, shade seeking behaviour (Ratnakaran et al 2017). In addition, body temperature as well behaviour has been affected by heat stress (Jara et al 2016, Tucker et al 2008).

In Chile, there is limited information regarding the effect of heat stress on dairy cattle. However, there is a risk of heat stress for the central region of Chile, but with a moderate to

Accepted: 09.08.2017.

anstituto de Producción Animal, Facultad de Ciencias Agrarias, Universidad Austral de Chile, Valdivia, Chile.

bepartamento de Ciencias Animales, Pontificia Universidad Católica de Chile, Santiago, Chile.

${ }^{\mathrm{c}}$ Mader Consulting LLC, Omaha, Estados Unidos.

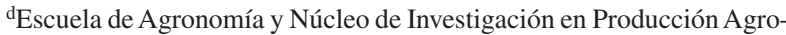
alimentaria, Universidad Católica de Temuco, Temuco, Chile.

*Corresponding author: R Arias; Independencia \#631, Valdivia, Chile; rodrigo.arias@uach.cl low risk in the southern regions (Arias and Mader 2010). The aforementioned is relevant considering that dairy farms located in the central region of Chile have a greater degree of intensification (total mixed rations and high production genotypes) and higher milk yield per cow than those located in the southern regions, where the systems are based on pasture. On the other hand, this subject is acquiring major attention and concern among producers due the changes in animal welfare requirements as well as changes observed on climate, with an increasing proportion of heat waves and extended periods of drought. We hypothesised that cows of the central region of Chile experience physiological and behavioural changes as consequence of the summer weather conditions. Therefore, the objectives of the study were to assess in two dairy genotypes changes on patterns of tympanic temperature, panting scores, respiration rates and utilisation of artificial shade during summer conditions in the central region of Chile.

\section{MATERIAL AND METHODS}

The study was conducted during the summer of 2011 at the dairy research farm of the Pontificia Universidad Católica de Chile, located in the foothills of the Andes mountains of the central region of Chile $\left(33^{\circ} 40^{\prime} 22.4^{\prime \prime} \mathrm{S}\right.$ $70^{\circ} 35^{\prime} 33.8^{\prime \prime} \mathrm{W}, 654$ meters above sea level). The study consisted of three periods of data collection: January 19 to $25^{\text {th }}$; February 5 to $8^{\text {th }}$; and March 20 to $24^{\text {th }}$. In each period, 6 Holstein $(\mathrm{H})$ and 6 Holstein $x$ Montbeliarde $(\mathrm{HM})$ cows were selected to receive a data logger device to collect tympanic temperatures (TT) and to study its behaviour. Thus, a total of 36 mature multiparous and healthy cows ( $67 \pm 6 \mathrm{~d}$ on milk), body condition score $=2.75$ to 3.00 ( 1 to 
5 scale) at the beginning of the experiment, were randomly selected from the commercial herd. All the cows were fed with the same diet three times a day (08:00 h, 11:30 h, and 18:00 h), which included (all expressed as DM/cow/ day) corn silage $(4.0 \mathrm{~kg})$, alfalfa soiling $(4.9 \mathrm{~kg})$, barley brewers $(2.9 \mathrm{~kg})$, and supplements $(0.25 \mathrm{~kg})$.

Animals were kept in open pens $(80 \mathrm{~m} \times 80 \mathrm{~m})$ with $\mathrm{ad}$ libitum access to water and shade, and milked three times per day (03:00, 12:00 and 18:00 h). However, milk yield was not considered in this analysis. The shading structure consisted of treated wood poles of approximately $4.0 \mathrm{~m}$ high, with a black raschel mesh ( $80 \%$ shade, $2.1 \mathrm{~m}$ wide) located over the wood poles, providing $2.8 \mathrm{~m}^{2}$ of shade by cow.

\section{TYMPANIC TEMPERATURE AND ANIMAL BEHAVIOR}

Each cow within each period received an iButton data logger device (Maxim Integrated Products Inc., CA, USA) located manually in its tympanic canal. The devices were programmed to collect TT at 10 minute intervals and subsequently compiled into hourly readings. The same cows used to collect TT were observed within each period to collect behavioural data. One trained observer recorded the proportion of cows using shade on the pen and also collected data of respiration rates (RR; breaths per minute; bpm). The RR were estimated by timing and counting 10 flank movements in each animal. Measurements of the panting score (PS) were also collected following the description of Mader and Davis (2002). First, the observer identified cows with the ibutton device within the herd, recording its location (shaded or unshaded), then recorded the count of flank movement and PS score independent of cow's location in the pen.

\section{ENVIRONMENTAL DATA COLLECTION AND THERMAL COMFORT INDICES}

Ambient temperature $\left(\mathrm{AT},{ }^{\circ} \mathrm{C}\right)$, wind speed $(\mathrm{WS}, \mathrm{m} / \mathrm{s})$, relative humidity $(\mathrm{RH}, \%)$, solar radiation $\left(\mathrm{SR}, \mathrm{W} / \mathrm{m}^{2}\right)$, and precipitation $(\mathrm{P}, \mathrm{mm} / \mathrm{d})$ ) were collected continuously at 10 minute intervals by using a weather station (U30 Hobo Onset, MA, USA) located at the dairy farm. Later, these data were compiled into hourly values to match TT dataset. Likewise, these climatic data were used to estimate three thermal comfort indices: temperature-humidity index (THI), adjusted THI ( $\left.\mathrm{THI}_{\text {adj }}\right)$, and comprehensive climate index (CCI) by using the following equations:

$$
\begin{gathered}
\mathrm{THI}=0.8 * \mathrm{AT}+((\mathrm{RH} / 100) *(\mathrm{AT}-14.4))+46.4 \\
(\text { equation } 1 ; \mathrm{Hahn} \text { et al }(2009)) \\
\mathrm{THI}_{\mathrm{adj}}=\underset{(\text { equation } 2 ; \text { Mader } \text { et al }(2006))}{4.51-(1.992 * \mathrm{WS})+(0.068 * \mathrm{SR})} \\
\quad \begin{array}{c}
\mathrm{CCI}=\mathrm{AT}+\mathrm{F}_{\mathrm{RH}}+\mathrm{F}_{\mathrm{WS}}+\mathrm{F}_{\mathrm{SR}} \\
(\text { equation 3; Mader } \text { et al }(2010))
\end{array}
\end{gathered}
$$

Where:

$\mathrm{F}_{\mathrm{RH}}$ corresponds to the correction factor for AT due to relative humidity;

$$
\begin{gathered}
\mathrm{e}^{\left(0.00182 * \mathrm{RH}+1.8 * 10^{-5 *} \mathrm{AT} * \mathrm{RH}\right) *\left(0.000054 * \mathrm{AT}^{2}+\right.} \\
0.00192 * \mathrm{AT}-0.0246) *(\mathrm{RH}-30)
\end{gathered}
$$

$\mathrm{F}_{\mathrm{WS}}$ corresponds to the correction factor for AT due to wind speed;

$$
\begin{aligned}
& {\left[\frac{-6.56}{\left\{\frac{1}{2.26 * \mathrm{WS}+0.23^{0.45} * 2.9+1.14 * 10^{-6 *} \mathrm{WS}^{2.5}-\log _{0.3}(2.26 * \mathrm{WS}+0.33)^{-2}}\right\}}\right]} \\
& -0.00566 * \mathrm{WS}^{2}+3.33
\end{aligned}
$$

and $\mathrm{F}_{\mathrm{SR}}$ corresponds to the correction factor for AT due to solar radiation.

$$
\begin{gathered}
0.0076 * \mathrm{SR}-0.00002 * \mathrm{SR} * \mathrm{AT}+0.00005 * \mathrm{AT}^{2} * \\
\sqrt{\mathrm{SR}}+0.1 * \mathrm{AT}-2
\end{gathered}
$$

The risk of thermal stress is given by the following categories of CCI (Mader et al 2010): No stress (CCI $\leq 25)$; Mild ( $>25$ and $\leq 30)$; Moderate $(>30$ and $\leq 35)$; Severe ( $>35$ and $\leq 40)$; Extreme $(>40$ and $\leq 45)$; and Extreme danger $(\mathrm{CCI}>45)$.

\section{STATISTICAL ANALYSIS}

During the study, eight data logger devices were lost (one per period for $\mathrm{H}$ genotype and 4 and 1 for HM genotype in periods 2 and 3 , respectively). In addition, data from 2 animals were removed from data set due to incomplete records of TT (less than $24 \mathrm{~h}$ /day or less than 4 days/ period), resulting in an unbalanced number of animals per period (total $n=26$ ). Meteorological and TT data were analysed by using a complete randomised experimental design arrangement, with each animal as experimental and observational unit. Additionally, a dummy variable (CCI condition) was created based on threshold of CCI defined by Mader et al (2010). Thus, hour of each day with $\mathrm{CCI} \leq 25^{\circ} \mathrm{C}$ were considered as "Normal", otherwise it was considered as "Stressful". Thus, genotype, moment of day (AM vs. PM), and CCI condition (Normal vs. Stressful) were considered like study factors in a factorial arrangement. In addition, TT was modeled using a repeated measurements analysis by using the MIXED procedure of SAS 9.4 (SAS Institute, Cary, NC) with TT as the dependent variable with genotype, hour and its interaction as independent variables in the model. The hour was the repeated measurement and the animal(genotype) statement was used as random effect. The period was not included in the model because different animals were used across 
the periods. Finally, categorical data were analysed by using a Chi square test (Likelihood ratio test). The level of significance for all the statistical analyses was 0.05 .

\section{RESULTS}

A summary of meteorological variables, thermal indices, and TT by period, type and moment of day are presented on table 1 . Most of climatic variables showed a decrease on periods 2 and 3 regarding period 1, with the exception of HR. In addition, even though AT reached values $>30^{\circ} \mathrm{C}$ during all days in periods 1 and 2, there was a considerable drop during night-time (mean $8.7^{\circ} \mathrm{C}$ ), representing over 20 points of fluctuation (Figure 1).

Figure 2 shows interaction period $\mathrm{x}$ CCI condition $\mathrm{x}$ genotype $(P=0.003)$. Cows of both genotypes showed the highest TT during stressful hours within each period. There were also interactions for genotype $\mathrm{x}$ CCI condition $(P<0.001)$, with HM cows showing greater TT than $\mathrm{H}$ cows in both CCI conditions; and for genotype $\mathrm{x}$ period

Table 1. Least square means \pm SEM of climate variables, tympanic temperature and thermal comfort indices by period, type and time of day during the summer time in central Chile.

\begin{tabular}{lcccccccc}
\hline Period & $\mathrm{TT},{ }^{\circ} \mathrm{C}$ & AT, ${ }^{\circ} \mathrm{C}$ & $\mathrm{RH}, \%$ & $\mathrm{WS}, \mathrm{m} / \mathrm{s}$ & $\mathrm{SR}, \mathrm{W} / \mathrm{m}^{2}$ & $\mathrm{THI}$ & $\mathrm{THI}_{\text {adj }}$ & $\mathrm{CCI},{ }^{\mathrm{o}} \mathrm{C}$ \\
\hline Period 1 & $37.83 \pm 0.02^{\mathrm{a}}$ & $20.5 \pm 0.2^{\mathrm{a}}$ & $63.8 \pm 0.8^{\mathrm{a}}$ & $0.21 \pm 0.08^{\mathrm{a}}$ & $353.3 \pm 10.4^{\mathrm{a}}$ & $65.0 \pm 0.3^{\mathrm{a}}$ & $71.5 \pm 0.3^{\mathrm{a}}$ & $23.1 \pm 0.3^{\mathrm{a}}$ \\
Period 2 & $37.55 \pm 0.02^{\mathrm{c}}$ & $19.7 \pm 0.3^{\mathrm{a}}$ & $67.7 \pm 0.9^{\mathrm{a}}$ & $0.12 \pm 0.08^{\mathrm{b}}$ & $323.6 \pm 14.9^{\mathrm{a}}$ & $64.2 \pm 0.4^{\mathrm{a}}$ & $70.6 \pm 0.4^{\mathrm{a}}$ & $21.7 \pm 0.5^{\mathrm{a}}$ \\
Period 3 & $37.71 \pm 0.01^{\mathrm{b}}$ & $16.2 \pm 0.2^{\mathrm{b}}$ & $69.9 \pm 0.7^{\mathrm{b}}$ & $0.13 \pm 0.08^{\mathrm{b}}$ & $246.9 \pm 9.7^{\mathrm{b}}$ & $58.9 \pm 0.3^{\mathrm{b}}$ & $64.8 \pm 0.4^{\mathrm{b}}$ & $16.5 \pm 0.4^{\mathrm{b}}$ \\
Mean & $37.74 \pm 0.01$ & $18.9 \pm 0.1$ & $66.6 \pm 0.4$ & $0.17 \pm 0.01$ & $312.5 \pm 6.6$ & $62.9 \pm 0.2$ & $69.2 \pm 0.2$ & $20.7 \pm 0.2$ \\
\hline \multicolumn{1}{l}{ Type/moment of day } & & & & & & & \\
\hline Normal & $37.53 \pm 0.01$ & $13.4 \pm 0.2$ & $82.4 \pm 0.3$ & $0.00 \pm 0.00$ & $47.2 \pm 2.52$ & $55.7 \pm 0.8$ & $60.6 \pm 0.2$ & $10.5 \pm 0.2$ \\
Stressful & $38.03 \pm 0.01$ & $27.0 \pm 0.3$ & $43.4 \pm 0.2$ & $0.41 \pm 0.01$ & $702.7 \pm 7.68$ & $73.3 \pm 0.1$ & $81.8 \pm 0.1$ & $35.6 \pm 0.1$ \\
AM & $37.45 \pm 0.01$ & $13.9 \pm 0.2$ & $81.2 \pm 0.4$ & $0.04 \pm 0.03$ & $168.8 \pm 6.61$ & $56.2 \pm 0.2$ & $61.8 \pm 0.3$ & $12.5 \pm 0.3$ \\
PM & $38.02 \pm 0.01$ & $23.9 \pm 0.2$ & $52.0 \pm 0.4$ & $0.30 \pm 0.08$ & $456.1 \pm 10.31$ & $69.5 \pm 0.2$ & $76.5 \pm 0.2$ & $28.8 \pm 0.3$ \\
\hline
\end{tabular}

$\mathrm{TT}=$ Tympanic temperature (genotypes pooled); $\mathrm{AT}=$ Ambient temperature; $\mathrm{RH}=$ Relative Humidity; WS= Wind speed; $\mathrm{SR}=\mathrm{Solar}$ radiation; THI= Temperature humidity index; $\mathrm{THI}_{\text {adj }}=$ Adjusted temperature humidity index; $\mathrm{CCI}=$ Comprehensive Climate Index .

Different letters within columns indicate significant differences between periods $(P<0.05)$. In addition, all variables showed significant differences when compared Normal vs. Stressful and AM vs. PM $(P<0.001)$.

Period 1 = January 19 to 25; Period 2 = February 05 to 08; and Period $3=$ March 20 to 24 of 2011.

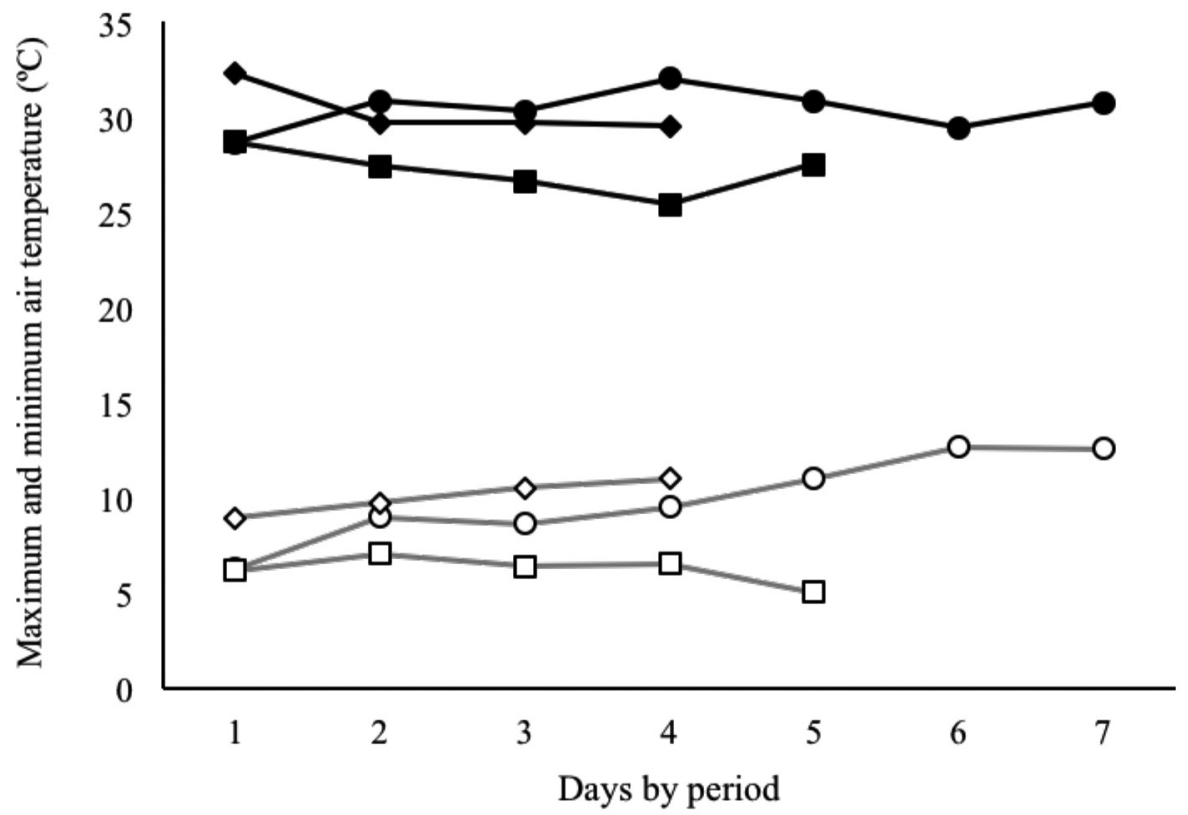

Figure 1. Daily maximum (dark line) and minimum (pale line) air temperatures for each day and period of collection data. Circles $=$ Period 1(January 19 to 25); Diamonds = Period 2 (February 05 to 08); and Squares = Period 3 (March 20 to 24 of 2011 ). 


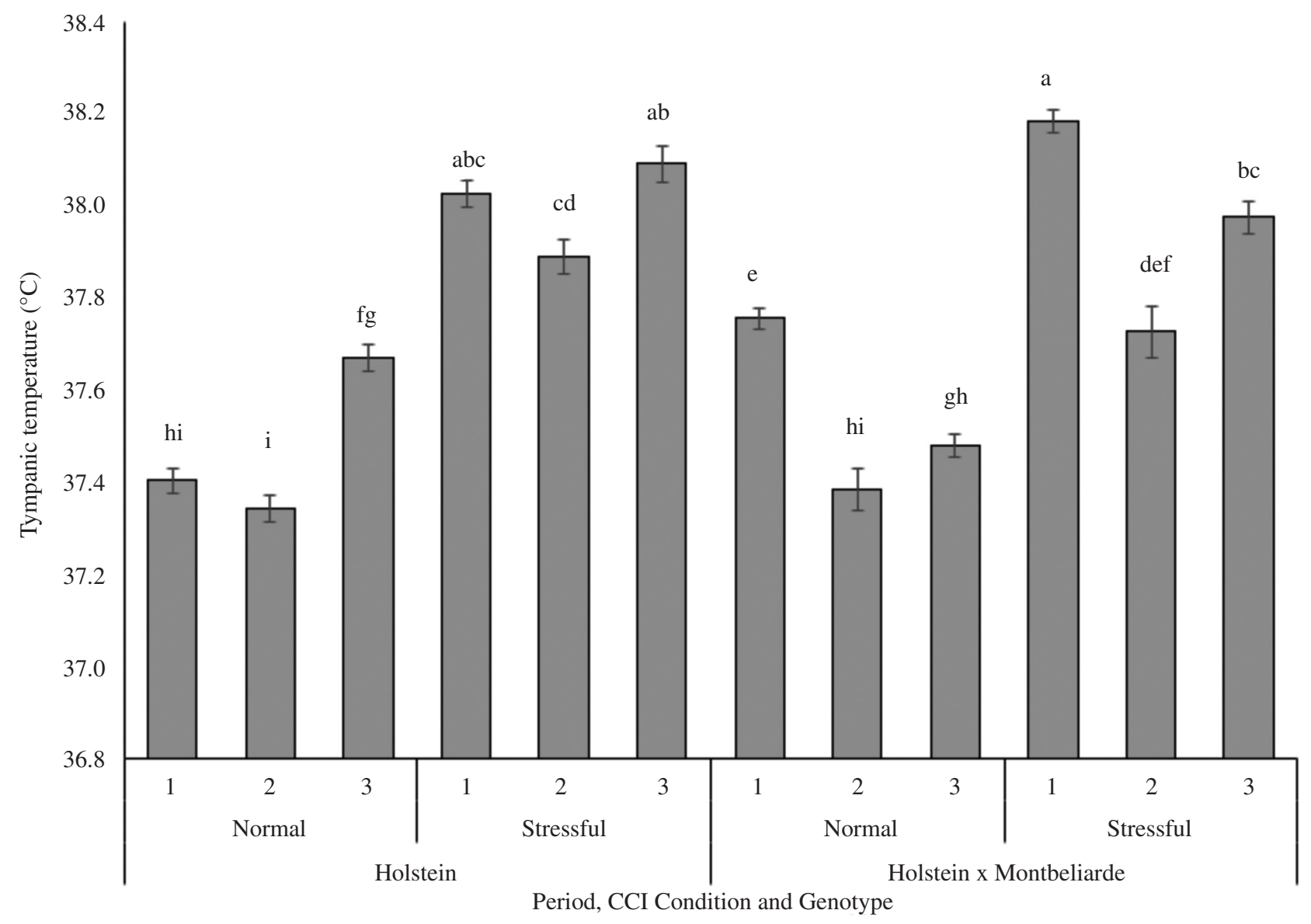

Figure 2. Least square means of tympanic temperatures of two dairy genotypes at each period and thermal index category (Comprehensive Climate Index $=$ CCI $)$ by period $\left(1=\right.$ January 19 to $25^{\text {th }} ; 2=$ February 5 to $8^{\text {th }}$; and $3=$ March 20 to $\left.24^{\text {th }}\right)$ in the central region of Chile. Different letters within columns indicate significant differences between periods $(P=0.0026)$.

$(P<0.001)$, with higher TT on period 1 in both genotypes. Finally, there was also an interaction of genotype $\mathrm{x}$ hour on TT $(P<0.001$; Figure 3$)$, with $\mathrm{H}$ cows showing lower TT during great part of the day (from 21:00 to 11:00; $P<0.100$ ).

Over $75 \%$ of cows were under shade during daytime. However, no differences were observed for morning vs. afternoon $(P=0.543)$ for pooled data. Nevertheless, the proportion of cows using shade increased when the hourly CCI category moved from "Normal" to "Mild " or "Moderate" stress $(P=0.049)$, but without differences between the last two categories. Similarly, this proportion also was higher $(P=0.007)$ during stressful condition when compared with normal condition (89.0 vs. $75.3 \%)$. As expected, the mean value of CCI for a stressful condition $\left(27.96 \pm 0.21^{\circ} \mathrm{C}\right)$ was greater than the normal condition $\left(21.40 \pm 0.28^{\circ} \mathrm{C} ; P<0.001\right)$. Cows showed a trend to reduce the use of shade during the third period of study $(P=0.094)$, coinciding with the end of the summer season and a lower SR.
The proportion of cows under shade across the periods was slightly higher during the morning vs. afternoon ( $86 \%$ AM vs. $79 \%$ PM). By the contrary, cows had higher RR during the afternoon when compared with the morning

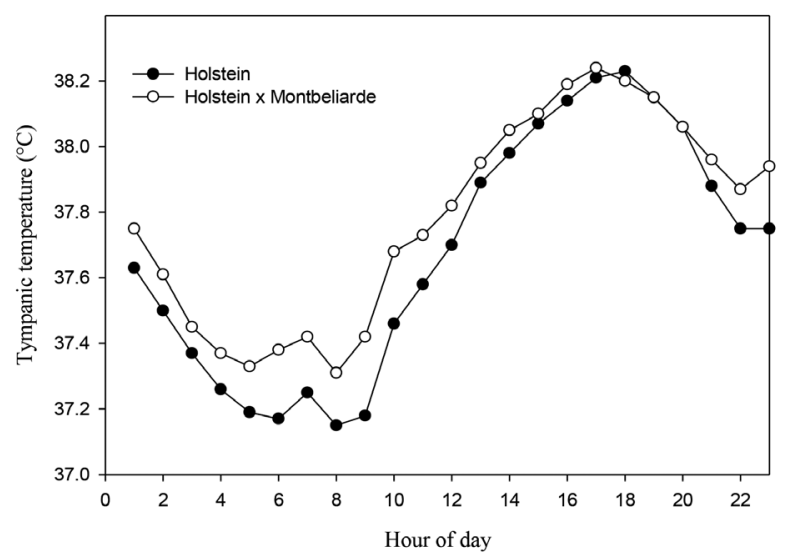

Figure 3. Least square means of tympanic temperature by genotype (All periods pooled: $P<0.10$ for hours $=0,1,2,3,4$, $6,7,8,9,10,11,21,22$ and $23 ; P<0.05$ for hour 5). 
$(67.51 \pm 1.13$ vs. $56.5 \pm 0.99$ bpm; $P<0.001)$. Likewise, RR increased $(P<0.001)$ from $59.98 \pm 1.00$ (Normal CCI condition) to $68.11 \pm 1.35 \mathrm{bpm}$ (Stressful CCI condition). When RR was compared among the hourly CCI categories showed an increase $(P<0.001)$ from $60.16 \pm 0.95 \mathrm{bpm}$ (Normal) to $69.13 \pm 2.73$ and $67.76 \pm 1.58$ for "Mild" and "Moderate" CCI categories, but without differences between them $(P>0.100)$. The PS changed across the day with a greater proportion of cows showing a $\mathrm{PS}=0$ during the morning (57.4\%), but decreasing during the afternoon (26.4\%), whereas cows on $\mathrm{PS}=1$ increased from $41.8 \%$ in the morning to $64.8 \%$ in the afternoon. The proportion of cows on $\mathrm{PS}=2$ increased more than forty folds, from $0.2 \%$ to $8.8 \%$ when comparing morning vs. afternoon. A similar pattern was observed when PS of cows was compared across periods, but no effects of shade on PS were observed $(P=0.765)$.

\section{DISCUSSION}

Heat stress has tremendous effect on production, health, and reproduction in lactating dairy cows, and has been largely ignored from a management standpoint (Tao and Dahl 2013). However, in many countries there is a lack of information about the impacts of heat stress on animal production and wellbeing. The present study is one of the firsts in Chile addressing this topic.

A possible explanation to the difference observed on TT between the genotypes (Figure 3 ) could be the better adaptation of the $\mathrm{H}$ cows to the environment when compared with the HM cows, that represent a newer genotype in the area of study. The higher TT during nighttime of HM cows could be the resultant of a lower capacity to dissipate the heat accumulated during daytime, as demonstrated by Aharoni et al (2006) who compared H vs. HM dairy cows during the summer season in Jordan. These authors reported differences between $\mathrm{H}$ and $\mathrm{HM}$ in their diurnal patterns of heat production, suggesting that heat tolerance of HM was lower than H cows. In our study, we did not measure the heat production.

The difference of TT between the morning vs. afternoon is in agreement with those reported by Vickers et al (2010), who measured vaginal temperatures of dairy cows. But differs from those reported by Aharoni et al (2005) who found no differences for rectal temperatures and RR. In the ruminants, rectal temperatures are considerably affected by rumen metabolism and do not represent a reliable index of the regulated temperature (Berman 1971). In fact, Burfeind et al (2010) concluded that measures of rectal temperature could be influenced by the procedure itself, type of thermometer, and the penetration depth into the rectum. Thus, some care is required when rectal temperatures are used as estimator of body temperature.

Although values of TT on "stressful" conditions were higher than under the "normal" condition, these are still within the normal range (Hillman 2009). We speculate that the cold nights observed during all the periods of data collection provide to the animals the opportunity to dissipate the heat accumulated during the daytime. In this context, some researchers have concluded that cattle that fail to or that do not cool down at night are prone to achieving greater body temperatures during hot days. Cattle that are prone to getting hot but can cool at night can keep peak body temperatures at or near those of cattle that tend to consistently maintain lower body temperatures (Mader and Johnson 2010, Mader et al 2010). The big drop in AT during night time, typical of the Andes foothills in that region ( $\geq 20^{\circ} \mathrm{C}$ of fluctuation), apparently allowed the cows to maintain TT within a normal range and to cope in better way the impact of heat load.

In this study, THI and $\mathrm{THI}_{\text {adj }}$ ranged from 57.0 to 67.3 and 62.9 to 73.8 respectively. These values that are under the threshold at which milk production (du Preez et al 1990, Johnson 1985) and dry matter intake (Johnson 1985) begin to decrease (THI $\geq 72$ ). Nevertheless, Zimbelman et al (2009) proposed a new THI threshold of 68 for high producing dairy cows ( $\geq 35 \mathrm{~L} /$ day). The previous is in agreement with those reported by Markovich (2012) in New Zealand, where milk production began to decrease at THI of 65 for $\mathrm{H}$ and 75 for Jerseys. Bernabucci et al (2014) also reported a reduction in milk production at THI from 65 to 76 depending of the parity of cows. There are other reports showing a range of multiple values of THI thresholds ranging from 69 to 78.2 (Bohmanova et al 2007, Bouraoui et al 2002, Dikmen and Hansen 2009, Johnson et al 1962, Ravagnolo et al 2000). However, it is important to mention that most of those reports are associated with the same genetic (Holstein Friesian). Nevertheless, other breeds are less sensitive to thermal stress than Holstein Friesian (Sharma et al 1983). Thus, differences in response to heat stress between genotypes can be attributed to varying levels of adaptability to hot environments (Kadzere et al 2002).

There is strong evidence that lactating cows increase RR during heat stress events or even they are able to reduce RR when they are properly cooled (Hillman et al 2001, Smith et al 2006). In our study, cows had RR slightly higher than those reported by Kendall et al (2007) for the shade treatment in a study conducted in New Zealand, with similar weather conditions, but it was lower than the uncooled treatment. The differences of RR between stressful vs. normal conditions herein reported are in agreement with those reported by Muller et al (1994), who found differences in RR for cows in hot days (AT $\geq$ $25.1^{\circ} \mathrm{C}$ ), but not for cool days (AT $\leq 25^{\circ} \mathrm{C}$ ). In our study, RR were also influenced by moment of day (AM vs. PM). The differences in RR herein presented as well as those reported by Bouraoui et al (2002), and by Muller et al (1994) suggest that cows were primarily subject to heat stress during those hours of the day when AT and SR reach maximum values, resulting in significant increases of RR. Thus, SR and AT are two important drivers and triggers 
of RR (Berman et al 1985, Harris et al 1960). The RR can be used as a valuable tool to assess the level of heat stress on cows. Finally, the high proportion of cows using shade, regardless of the moment of day, implies that cows uses this mechanism to cope with heat load of daytime. In addition, when data were analysed by period, there was a trend to seek shade during the afternoons $(P=0.073)$ in period 1 (January) which coincides with the highest values of SR. Based on the results of this study we can indicate that cows of both genotypes showed a slight degree of heat stress in Central region of Chile, particularly during daytime. However, they were able to cope with it because of the strong drop on AT during nighttime as well as by the using of shade.

\section{REFERENCES}

Aharoni Y, Brosh A, Harari Y. 2005. Night feeding for high-yielding dairy cows in hot weather: effects on intake, milk yield and energy expenditure. Livest Prod Sci 92, 207-219.

Aharoni Y, Brosh A, Kafchuk E. 2006. The efficiency of utilization of metabolizable energy for milk production: a comparison of Holstein with F1 Montbeliarde $\times$ Holstein cows. Anim Sci 82, 101-109.

Arias RA, Mader TL, Escobar PC. 2008. Climatic factors affecting cattle performance in dairy and beef farms. Arch Med Vet 40, 7-22.

Arias RA, Mader TL. 2010. Determination of potential risk of heat stress of cattle in four locations of Central and Southern Chile. Arch Med Vet 42, 33-39.

Berman A. 1971. Thermoregulation in intensively lactating cows in near-natural conditions. J Physiol 215, 477-489.

Berman A, Folman Y, Kaim M, Mamen M, Herz Z, et al. 1985. Upper critical temperatures and forced ventilation effects for high-yielding dairy cows in a subtropical climate. J Dairy Sci 68, 1488-1495.

Bernabucci U, Biffani S, Buggiotti L, Vitali A, Lacetera N, et al. 2014. The effects of heat stress in Italian Holstein dairy cattle. $J$ Dairy Sci 97, 471-486.

Bohmanova J, Misztal I, Cole JB. 2007. Temperature-humidity indices as indicators of milk production losses due to heat stress. J Dairy Sci 90, 1947-1956.

Bouraoui R, Lahmar M, Majdoub A, Djemali M, Belyea R. 2002. The relationship of temperature-humidity index with milk production of dairy cows in a Mediterranean climate. Anim Res 51, 479-491.

Burfeind O, von Keyserlingk MAG, Weary DM, Veira DM, Heuwieser W. 2010. Short communication: Repeatability of measures of rectal temperature in dairy cows. J Dairy Sci 93, 624-627.

Collier RJ, Dahl GE, VanBaale MJ. 2006. Major advances associated with environmental effects on dairy cattle. J Dairy Sci 89, 1244-1253.

Dikmen S, Hansen PJ. 2009. Is the temperature-humidity index the best indicator of heat stress in lactating dairy cows in a subtropical environment? J Dairy Sci 92, 109-116.

du Preez J, Hattingh PJ, Giesecke WH, Eisenberg BE. 1990. Heat stress in dairy cattle and other livestock under southern African conditions. III. Monthly temperature-humidity index mean values and their significance in the performance of dairy cattle. Onderstepoort $J$ Vet Res 57, 243-248.

Hahn GL, Gaughan JB, Mader TL, Eigenberg RA. 2009. Thermal indices and their applications for livestock environments. In: DeShazer JA (eds). Livestock energetics and thermal environmental management. ASABE, St. Joseph, MI, USA, Pp 113-130.

Harris DL, Shrode RR, Rupel IW, Leighton RE. 1960. A study of solar radiation as related to physiological and production responses of lactating Holstein and Jersey Cows. J Dairy Sci 43, 1255-1262.

Hillman PE, Gebremedhin KG, Parkhurst AM, Fuquay J, Willard S. 2001. Evaporative and convective cooling of cows in a hot and humid environment. Livestock Environment VI: Proceedings of the 6th International Symposium, Pp 343-350.

Hillman PE. 2009. Thermoregulatory physiology. In: DeShazer JA (eds). Livestock energetics and thermal enviromental management. ASABE, Moscow, Idaho, USA, Pp 23-48.

Jara IE, Keim JP, Arias RA. 2016. Behaviour, tympanic temperature and performance of dairy cows during summer season in southern Chile. Arch Med Vet 48, 113-118.

Johnson HD, Ragsdale AC, Berry IL, Shanklin MD. 1962. Effect of various temperature-humidity combinations on milk production of Holstein cattle. Agricultural Experimental Station Research Bulletin No 791. College of Agriculture AES, University of Missouri, Columbia, USA.

Johnson HD. 1985. Physiological responses and productivity of cattle In: Yousef MK (eds). Stress physiology in livestock basic principles. CRC Press, Boca Raton, Florida, Pp 4-19.

Kadzere CT, Murphy MR, Silanikove N, Maltz E. 2002. Heat stress in lactating dairy cows: a review. Livest Prod Sci 77, 59-91.

Kendall PE, Verkerk GA, Webster JR, Tucker CB. 2007. Sprinklers and shade cool cows and reduce insect-avoidance behaviour in pasture-based dairy systems. J Dairy Sci 90, 3671-3680.

Mader TL, Davis MS. 2002. Wind speed and solar radiation corrections for the temperature-humidity index. Proc 15th Conf Biomet and Aerobiol, Joint with 16th Int Cong on Biomet, Boston, MA, USA, Pp 154-157.

Mader TL, Davis MS, Brown-Brandl T. 2006. Environmental factors influencing heat stress in feedlot cattle. J Anim Sci 84, 712-719.

Mader TL, Johnson L. 2010. Tympanic temperature profile of confined beef cattle. Nebraska Beef Report. University of Nebraska-Lincoln, Nebraska, Lincoln, USA.

Mader TL, Johnson LJ, Gaughan JB. 2010. A comprehensive index for assessing environmental stress in animals. J Anim Sci 88, 2153-2165.

Markovich T. 2012. Heat/Cold stress management \& animal welfare in grazing dairies. Proceedings of the 84 Annual Western Veterinary Conference, Las Vegas, NE, USA, Pp 1-4.

Muller CJC, Botha JA, Coetzer WA, Smith WA. 1994. Effect of shade on various parameters of Friesian cows in a Mediterranean climate in South Africa. 2. Physiological responses. S Afr J Anim Sci 24, 56-60.

Ratnakaran AP, Sejian V, Sanjo Jose V, Vaswani S, Bagath M, et al. 2017. Behavioral responses to livestock adaptation to heat stress challenges. Asian J Anim Sci 11, 1-13.

Ravagnolo O, Misztal I, Hoogenboom G. 2000. Genetic component of heat stress in dairy cattle, development of heat index function. J Dairy Sci 83, 2120-2125.

Sharma AK, Rodriguez LA, Mekonnen G, Wilcox CJ, Bachman KC, et al. 1983. Climatological and genetic effects on milk composition and yield. J Dairy Sci 66, 119-126.

Silanikove N. 2000. Effect of heat stress on the welfare of extensively managed domestic ruminants. Livest Prod Sci 67, 1-18.

Smith TR, Chapa A, Willard S, Herndon C, Jr., Williams RJ, et al. 2006. Evaporative tunnel cooling of dairy cows in the southeast. I: Effect on body temperature and respiration rate. J Dairy Sci 89, 3904-3914.

St-Pierre NR, Cobanov B, Schnitkey G. 2003. Economic losses from heat stress by US livestock industries. J Dairy Sci 86, E52-77.

Tao S, Dahl GE. 2013. Invited review: Heat stress effects during late gestation on dry cows and their calves. J Dairy Sci 96, 4079-4093.

Tucker CB, Rogers AR, Schütz KE. 2008. Effect of solar radiation on dairy cattle behaviour, use of shade and body temperature in a pasture-based system. Appl Anim Behav Sci 109, 141-154.

Vickers LA, Burfeind O, von Keyserlingk MAG, Veira DM, Weary DM, et al. 2010. Technical note: Comparison of rectal and vaginal temperatures in lactating dairy cows. J Dairy Sci 93, 5246-5251.

West JW. 2003. Effects of heat-stress on production in dairy cattle. J Dairy Sci 86, 2131-2144.

Zimbelman RB, Rhoads RP, Rhoads ML, Duff GC, Baumgard LH, et al. 2009. A re-evaluation of the impact of temperature humidity index (THI) and black globe humidity index (BGHI) on milk production in high producing dairy cows. Proceedings of the 24th Southwest Nutrition and Management Conference Tempe, AZ, USA, Pp 158-169. 